\title{
Memantine Reverses Social Withdrawal Induced by Ketamine in Rats
}

\author{
Ezequiel Uribe ${ }^{1,2 *}$, José Landaeta ${ }^{1}$, Richard Wix ${ }^{1}$ and Antonio Eblen ${ }^{1}$ \\ ${ }^{1}$ Laboratorio de Neurofisiología, Escuela De Ciencias Biomédicas y Tecnológicas Dr. Guillermo Mujica Sevilla, \\ Facultad de Ciencias de la Salud, Universidad de Carabobo, Valencia, ${ }^{2}$ Hospital Dr. Rafael González Plaza, \\ Departamento de Neuropsiquiatría. INSALUD, Gobernación del Estado Carabobo. Edo. Carabobo 2001, Venezuela
}

\begin{abstract}
The objective of this study was to determine the effect of memantine on schizophrenia-like symptoms in a ketamine-induced social withdrawal model in rats. We examined therapeutic effects of memantine, an NMDA antagonist, and haloperidol, a classic antipsychotic drug, on this behavioral model. Administration of memantine (10 or $\left.15 \mathrm{mg} \cdot \mathrm{kg}^{-1}\right)$ significantly reduced ketamine-induced social withdrawal, and this effect was more effective than that of haloperidol $\left(0.25 \mathrm{mg} \cdot \mathrm{kg}^{-1}\right)$ by restoring the social interaction between rats with no modification in general motor activity. These results suggest that memantine could have a therapeutic potential for schizophrenia.
\end{abstract}

Key words: experimental psychosis, ketamine, NMDA, haloperidol, social interaction test

\section{INTRODUCTION}

Schizophrenia is a polygenic, multi-factorial disease whose etiology remains unknown. The wide range of symptoms and differences in the course and prognosis suggest that schizophrenia arises from the dysfunction of several neurotransmitter systems, generating a wide range of neurophysiological alterations that are not identifiable in all patients. Since its inception, schizophrenia has been managed with dopamine antagonists, which effectively reverses positive symptoms, but does not improve residual symptoms produced for the long term, such as cognitive impairment, social withdrawal, affective dysregulation, and disability [1]. In addition, $10-30 \%$ of patients do not improve with dopamine antagonists and become refractory to treatment

Received February 8, 2013, Revised March 10, 2013,

Accepted March 11, 2013

${ }^{*}$ To whom correspondence should be addressed. TEL: 58-241-871-2437, FAX: 58-412-482-4444

e-mail: ezequiel.uribe@hotmail.com; jcuriven@hotmail.com
[1].

Recently, the glutaminergic system has been suggested to be linked with schizophrenia, after it was shown that N-methylD-aspartate (NMDA) receptor antagonists such as ketamine, phencyclidine, and MK 801 were beneficial for both positive and negative symptoms of the disease [2]. Yet, the only available treatment for schizophrenia is the drugs that act on the dopaminergic system, and no alternative drugs that act on other neurotransmitter systems are available. Repeated treatment of ketamine in rats generates social withdrawal and aggression, alterations which are reminiscent of the symptoms of schizophrenia in humans [3]. In the present study, we attempted to reproduce a model of psychosis by treatment with ketamine in rats. After establishment of psychosis model, we assessed reversibility of the condition with memantine, a modulator of the NMDA receptor, and compared the effect with that of haloperidol, a potent dopamine antagonist. The degrees of social withdrawal were analyzed in the social interaction test (SIT) and quantified. 


\section{MATERIALS AND METHODS}

\section{Animals}

Male Sprague-Dawley rats (weight, 150-200 g) were placed in separate cages with food and water provided ad libitum, and room temperature of $22^{\circ} \mathrm{C}$. They were remained in auditory and olfactory contact with the other rats until use.

\section{The social interaction test (SIT)}

The social interaction test (SIT) was performed in an open stainless steel cage $(52 \times 42 \times 20 \mathrm{~cm})$ by following the method of Becker et al. [3]. The floor of the cage was uniformly distributed with rice shells. A digital camera (PCwebCam, Genius ${ }^{\mathrm{TM}}$ ) was placed over the cage attached to a laptop to film the behavior of rats at 30 frames/second. Ambient illumination was uniformly distributed at approximately 30 lux with a light-dark scheme of $12 \mathrm{~h}$ light/12 h dark. After the third day of habituation in the test room, rats were familiarized with the SIT scene without recording. The laboratory was silent while the tests were performed.

On next day, recording was carried out for 7 minutes after placing pairs of rats in the cage. Initial tests were performed in pairs of randomly selected rats without medication. Then, the rats were divided into two groups: one group received $30 \mathrm{mg} \cdot \mathrm{kg}^{-1}$

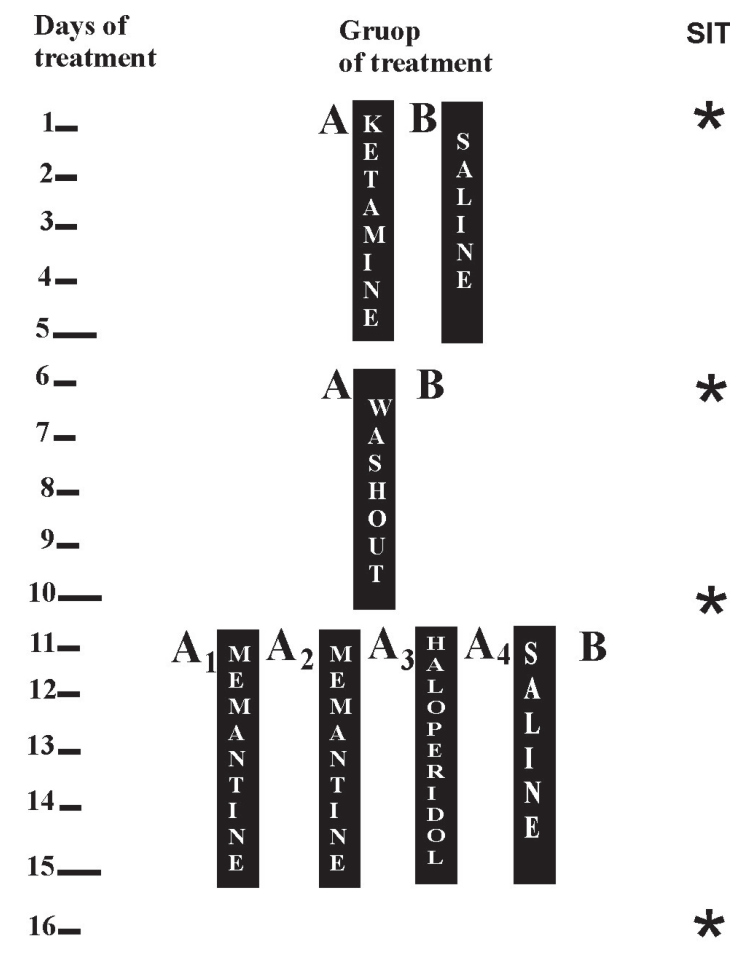

Fig. 1. $A(n: 20) B(n: 20), A_{1}$ (n: 5): memantine $10 \mathrm{mg} \cdot \mathrm{kg}^{-1}, A_{2}$ (n: 5): memantine $10 \mathrm{mg} \bullet \mathrm{kg}^{-1}, \mathrm{~A}_{3}(\mathrm{n}: 5)$ : haloperidol $0.25 \mathrm{mg} \cdot \mathrm{kg}^{-1}, \mathrm{~A}_{4}$ : saline. ketamine intraperitoneally (i.p), $(n=20)$ for 5 days and the other group $(n=20)$ received $0.9 \%$ saline i.p. for 5 days. The SIT was performed with pairs of rats randomly selected from each group. Treatment was suspended for 5 days; at the end of which the SIT was repeated under the same pair conditions. Then, the ketamine group $(n=20)$ was divided into four groups of five rats, each received memantine $\left(10 \mathrm{mg} \bullet \mathrm{kg}^{-1}\right)$, memantine $\left(15 \mathrm{mg} \bullet \mathrm{kg}^{-1}\right)$, haloperidol $\left(0.25 \mathrm{mg} \cdot \mathrm{kg}^{-1}\right)$ or $0.9 \% \mathrm{NaCl}$ solution, all diluted in 1 $\mathrm{mL}$ of $0.9 \%$ saline and administered i.p daily for 5 days after which the SIT was conducted again (Fig. 1).

Video files taken during each test (7 min test) were analyzed using Tracker V4.05 software by measuring the distance $(\mathrm{cm})$ between the pair of rats and the total distance traveled $(\mathrm{cm})$ for each rat during the test. These determinations were calibrated in two-dimensions (ordinate and abscissa). Distance measurements were taken from image frames with $1 \mathrm{~Hz}$ frequency, generating a total of 420 measurements (8,400 measurements/group) for each variable. The speed of each rat during the SIT was calculated from their total traveled distance and time used for it, expressed as $\mathrm{cm}$. $\mathrm{s}^{-1}$. Distance between rats (DBR) was used as the schizophrenia sign, whereas total traveled distance (TTD) and speed during SIT were used to assess the impact of the drugs on motor activity.

\section{Statistical analysis}

The data were processed using STATISTICA 8 software and parametric descriptive statistics. Pearson's correlations were performed. A $\mathrm{p}<0.05$ was considered significant for all tests. Comparisons of quantitative variables for each treatment group were performed using analysis of variance (ANOVA) to reject the null hypothesis and conclude that at least two groups were different from each other. Post-hoc t-tests (LSD test) were performed to adjust for the inflated probability of a Type I error.

\section{RESULTS}

\section{Establishment of a rat model of psychosis-like behavior}

A rat model of psychosis-like behavior was established by repea-

Table 1. Distance between rats in the groups immediate after ketamine treatment and 5 days after washout

\begin{tabular}{lccc}
\hline & $\begin{array}{c}\text { Control } \\
(\mathbf{n = 2 0})\end{array}$ & $\begin{array}{c}\text { Ketamine } \\
(\mathbf{n = 2 0 )}\end{array}$ & $\mathbf{p}$ \\
\hline After treatment for 5 days & $18.49(35.5 \%)$ & $19.88(38.2 \%)$ & 0.0001 \\
After 5 days of washout & $18.28(35.1 \%)$ & $20.34(39.1 \%)$ & 0.0001 \\
\hline
\end{tabular}

Distance between rats was recorded after treatment with ketamine for 5 days and after 5 days of washout. Data were presented as means (\% of total distance) in cm. Numbers of animals for each group: 20 . 
ted treatment with ketamine as scheduled (Fig. 1). Ketaminewithdrawal significantly reduced social interaction between the rats by increasing the distance between them during the SIT. These changes remained for 5 days of ketamine withdrawal (Table 1).

\section{Examination of the effects of memantine and haloperidol}

Memantine $\left(10 \mathrm{mg} \cdot \mathrm{kg}^{-1}\right)$ reduced the distance between rats

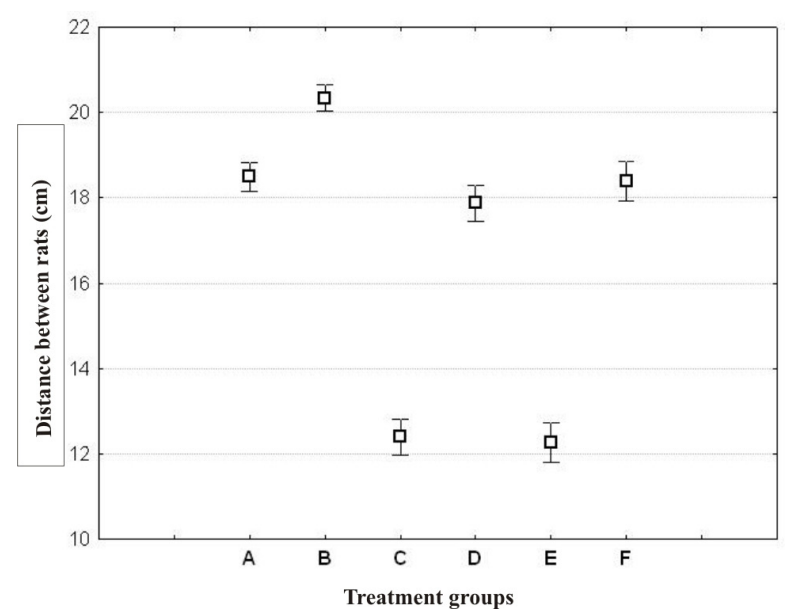

Fig. 2. Distance between rats for treatment groups during the social interaction test. Distance between rats was expressed as means $\pm \mathrm{SD}$ in $\mathrm{cm}$. Treatment groups: (A) rats without pharmacological intervention, (B) 5 days after ketamine withdrawal, (C) $10 \mathrm{mg} \cdot \mathrm{kg}^{-1}$ memantine after ketamine withdrawal, (D) saline after ketamine withdrawal, (E) $15 \mathrm{mg}$ • $\mathrm{kg}^{-1}$ memantine after ketamine withdrawal, (F) $0.25 \mathrm{mg} \cdot \mathrm{kg}^{-1}$ haloperidol after ketamine withdrawal.

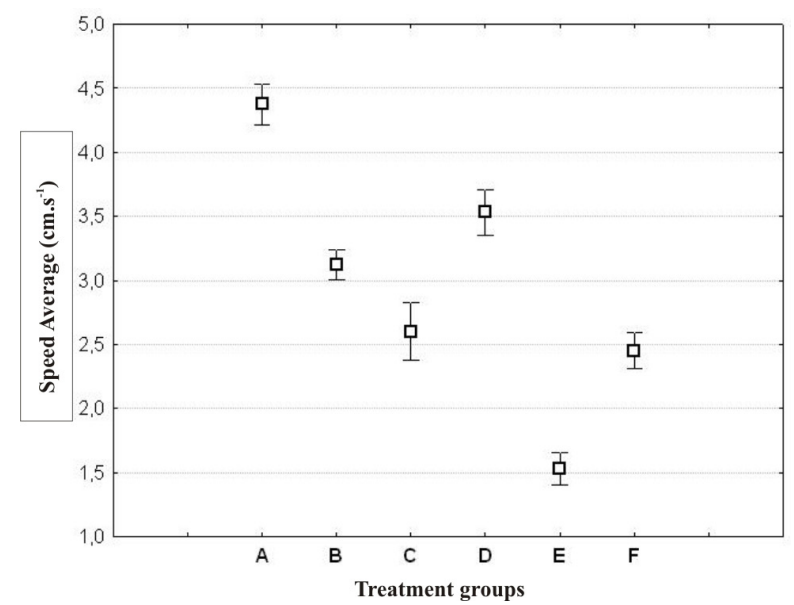

Fig. 3. Average speed for treatment groups during the social interaction test. Average speed was expressed as means $\pm \mathrm{SD}$ in $\mathrm{cm} \cdot \mathrm{s}^{-1}$. Treatment groups: (A) rats without pharmacological intervention, (B) 5 days after ketamine withdrawal, (C) $10 \mathrm{mg} \cdot \mathrm{kg}^{-1}$ memantine after ketamine withdrawal , (D) placebo after ketamine withdrawal, (E) $15 \mathrm{mg} \cdot \mathrm{kg}^{-1}$ memantina after ketamine withdrawal, (F) $0,25 \mathrm{mg} \bullet \mathrm{kg}^{-1}$ haloperidol after ketamine withdrawal.
(DBR) during the SIT after ketamine withdrawal, and this effect was greater than that shown by the placebo (saline). No significant differences were observed in DBR after administering 10 or 15 $\mathrm{mg} \cdot \mathrm{kg}^{-1}$ memantine but $10 \mathrm{mg} \cdot \mathrm{kg}^{-1}$ induced a greater decrease in the DBR than that of haloperidol (Fig. 2). Ketamine also produced a reduction in the distance traveled per second (Fig. 3) compared with that in the control, and this effect persisted after ketamine withdrawal. No significant difference was found between the groups. Memantine induced a greater reduction in distance traveled per second than that in the placebo group, and this effect was more intense for the $15 \mathrm{mg} \cdot \mathrm{kg}^{-1}$ memantine than that in the $10 \mathrm{mg} \cdot \mathrm{kg}^{-1}$ memantine group (Table 2). The reduction in TTD was higher for the memantine groups than that for haloperidol. Data analysis with ANOVA followed by a post hoc test (LSD test) showed no statistical correlation between DBR and rat speed during the SIT (Table 3).

\section{DISCUSSION}

The ketamine-induced psychosis model in rats reproduces behavioral symptoms that mimic schizophrenic psychosis in humans [3], as well as the primary pathophysiological changes generated by this disease [4]. When the membrane NMDA receptor is blocked by ketamine in GABAergic interneurons, there is a failure to correctly interpret the degree of excitation of pyramidal neurons; resulting in an excessive glutamate action; thus, inducing an overstimulation of the ventral tegmental area and finally, the classic hyper-dopaminergic state characteristic of schizophrenia [5]. Ketamine has hepatic clearance of 19.1 $\mathrm{ml} \cdot \min ^{-1} \cdot \mathrm{kg}^{-1}$, which ensures the excretion of its eight active metabolites about $24 \mathrm{~h}$ after administration [6]. Ketamine, which blocks NMDA, is known to generate long lasting molecular changes in the brain at least 14 days after complete withdrawal [4].

Table 2. Distance between rats and speed measured in groups and/or experimental phases

\begin{tabular}{lll}
\multicolumn{1}{c}{ Drug } & DBR & Speed \\
\hline Controls & 18.49 & 4.37 \\
Ketamine without other drug & 19.88 & 3.58 \\
Memantine $10 \mathrm{mg} \cdot \mathrm{kg}^{-1}$ & $12.39^{\mathrm{a}, \mathrm{b}, \mathrm{c}}$ & $1.87^{\mathrm{a}, \mathrm{b}, \mathrm{c}}$ \\
Memantine $15 \mathrm{mg} \cdot \mathrm{kg}^{-1}$ & 12.25 & 1.26 \\
Haloperidol & 18.39 & 2.55 \\
Placebo & 17.88 & 4.07 \\
\hline
\end{tabular}

Distance between rats (DBR) was presented by means in $\mathrm{cm}$ and speed was means in $\mathrm{cm} \cdot \mathrm{s}^{-1}$. The differences between the values of the groups treated with 10 and $15 \mathrm{mg} \cdot \mathrm{kg}^{-1}$ memantine were not significant. ${ }^{\mathrm{a}} \mathrm{p}<0.0001$ compared with control group; ${ }^{\mathrm{b}} \mathrm{p}<0.0001$ compared with placebo group; ${ }^{c} \mathrm{p}<0.0001$ compared with haloperidol group. 
Table 3. Post hoc analysis of the distance between rats and average speed of rats during the social interaction test

\begin{tabular}{|c|c|c|c|c|c|c|c|}
\hline \multicolumn{8}{|c|}{ (A) } \\
\hline & (0) 18,493 & (1) 19,697 & (2) 19,639 & (3) 12,394 & (4) 17,881 & (5) 12,259 & (6) 18,388 \\
\hline 0 & & 0.000000 & 0.000000 & 0.000000 & 0.023431 & 0.000000 & 0.698521 \\
\hline 1 & 0.000000 & & 0.708130 & 0.000000 & 0.000000 & 0.000000 & 0.000000 \\
\hline 2 & 0.000000 & 0.708130 & & 0.000000 & 0.000000 & 0.000000 & 0.000000 \\
\hline 3 & 0.000000 & 0.000000 & 0.000000 & & 0.000000 & 0.684207 & 0.000000 \\
\hline 4 & 0.023431 & 0.000000 & 0.000000 & 0.000000 & & 0.000000 & 0.103669 \\
\hline 5 & 0.000000 & 0.000000 & 0.000000 & 0.684207 & 0.000000 & & 0.000000 \\
\hline 6 & 0.698521 & 0.000000 & 0.000000 & 0.000000 & 0.103669 & 0.000000 & \\
\hline \multicolumn{8}{|c|}{ (B) } \\
\hline & (0) 4,5938 & (1) 3,6968 & (2) 3,5560 & (3) 1,8781 & (4) 4,0717 & (5) 1,2605 & (6) 2,5541 \\
\hline 0 & & 0.000000 & 0.000000 & 0.000000 & 0.000001 & 0.000000 & 0.000000 \\
\hline 1 & 0.000000 & & 0.023751 & 0.000000 & 0.000140 & 0.000000 & 0.000000 \\
\hline 2 & 0.000000 & 0.023751 & & 0.000000 & 0.000000 & 0.000000 & 0.000000 \\
\hline 3 & 0.000000 & 0.000000 & 0.000000 & & 0.000000 & 0.000003 & 0.000000 \\
\hline 4 & 0.000001 & 0.000140 & 0.000000 & 0.000000 & & 0.000000 & 0.000000 \\
\hline 5 & 0.000000 & 0.000000 & 0.000000 & 0.000003 & 0.000000 & & 0.000000 \\
\hline 6 & 0.000000 & 0.000000 & 0.000000 & 0.000000 & 0.000000 & 0.000000 & \\
\hline
\end{tabular}

Post hoc analysis of the distance between rats (A) and speed (B) using LSD test. (A) Probabilities for post hoc tests error: between MS=102.17, $\mathrm{df}=28,973$. (B) Probabilities for post hoc tests Error: Between $\mathrm{MS}=16.274, \mathrm{df}=28,973$. Groups of treatment: (0) Rats without pharmacological intervention, (1) 5 days after ketamine withdrawal, (2) after ketamine withdrawal, (3) memantine $10 \mathrm{mg} \cdot \mathrm{kg}^{-1}$ after ketamine withdrawal, (4) placebo after ketamine withdrawal, (5) memantina $15 \mathrm{mg} \cdot \mathrm{kg}^{-1}$ after ketamine withdrawal, (6) Haloperidol $0.25 \mathrm{mg} \cdot \mathrm{kg}^{-1}$ after ketamine withdrawal.

In our study, memantine was administered at $10 \mathrm{mg} \cdot \mathrm{kg}^{-1}$ after ketamine treatment and memantine treatment resulted in a greater reversal of social isolation than that of the placebo or haloperidol $\left(0.25 \mathrm{mg} \cdot \mathrm{kg}^{-1}\right)$. This antipsychotic action did not show a doseeffect. Memantine induced a reduction in the total traveled distance, and a dose dependent effect at 10 and $15 \mathrm{mg} \bullet \mathrm{kg}^{-1}$. Thus, the sedative effect of memantine must be considered to explain this observation. Although previous studies described the use of higher doses of memantine [7], all of our rats died in a preliminary study at doses $>30 \mathrm{mg} \cdot \mathrm{kg}^{-1}$.

No correlation was observed between the distance traveled per second (speed) and DBR (social isolation), suggesting that the effect of memantine on this ketamine-induced psychotic symptom probably was not due to an action of memantine on rat motility. In addition, regarding that a social withdrawal model induced by ketamine in rats is an approach to behavioral changes of schizophrenia in human, these data suggest that memantine has a therapeutic potential for this disease.

The therapeutic effect of memantine in ketamine-induced psychosis model of schizophrenia suggests the importance of glutamatergic dysfunction in schizophrenia. In fact, glutamatergic dysfunction in schizophrenia has been suggested to be one of the neurotransmitter systems involved. Current evidence suggests that the wide variety of clinical conditions among patients with schizophrenia could be caused by different endophenotypes [8], which in turn, induce differences in the response to antipsychotic treatments. For example, 10-30\% of patients with schizophrenia become resistant to conventional antipsychotic treatment [1], but respond to clozapine, which is an atypical antipsychotic drug with a high impact on NMDA receptor modulation [9], suggesting that these patients may have a different endophenotype that requires an alternative pharmacological intervention.

\section{REFERENCES}

1. Lehman AF, Lieberman JA, Dixon LB, McGlashan TH, Miller AL, Perkins DO, Kreyenbuhl J; American Psychiatric Association; Steering Committee on Practice Guidelines (2004) Practice guideline for the treatment of patients with schizophrenia, second edition. Am J Psychiatry 161:1-56.

2. Krystal JH, Karper LP, Seibyl JP, Freeman GK, Delaney R, Bremner JD, Heninger GR, Bowers MB Jr, Charney DS (1994) Subanesthetic effects of the noncompetitive NMDA antagonist, ketamine, in humans. Psychotomimetic, perceptual, cognitive, and neuroendocrine responses. Arch Gen Psychiatry 51:199-214.

3. Becker A, Grecksch G, Bernstein HG, Höllt V, Bogerts B (1999) Social behaviour in rats lesioned with ibotenic acid in the hippocampus: quantitative and qualitative analysis. Psychopharmacology (Berl) 144:333-338. 
4. Keilhoff G, Becker A, Grecksch G, Wolf G, Bernstein HG (2004) Repeated application of ketamine to rats induces changes in the hippocampal expression of parvalbumin, neuronal nitric oxide synthase and cFOS similar to those found in human schizophrenia. Neuroscience 126:591-598.

5. Homayoun H, Moghaddam B (2007) NMDA receptor hypofunction produces opposite effects on prefrontal cortex interneurons and pyramidal neurons. J Neurosci 27:1149611500 .

6. Evers A, Crowder M. (2011) Generals anesthetics. In: Goodman \& Gilman's the pharmacological basis of therapeutics,
12 edition (Brunton LL, Chabner B, Knollmann BC, eds), pp 867-875. McGraw-Hill, New York.

7. Creeley C, Wozniak DF, Labruyere J, Taylor GT, Olney JW (2006) Low doses of memantine disrupt memory in adult rats. J Neurosci 26:3923-3932.

8. Gottesman II, Gould TD (2003) The endophenotype concept in psychiatry: etymology and strategic intentions. Am J Psychiatry 160:636-645.

9. Olney JW, Farber NB (1994) Efficacy of clozapine compared with other antipsychotics in preventing NMDA-antagonist neurotoxicity. J Clin Psychiatry 55 Suppl B:43-46. 